\title{
Accessing Investigational Products Outside of a Trial: Considerations for Neuromuscular Providers
}

\author{
R. S. Bedlack, MD, PhD ${ }^{1, *} \odot$ \\ M. E. Cudkowicz, $M D^{2}$ \\ S. Paganoni, MD, PhD \\ H. Khan-Tareen ${ }^{3}$ \\ J. A. Andrews, MD, MSC ${ }^{4}$
}

\author{
Address \\ *,1Duke University, Durham, NC, USA \\ Email: Richard.bedlack@duke.edu \\ ${ }^{2}$ Mass General, Boston, MA, USA \\ ${ }^{3} \mathrm{New}$ York Medical College, Valhalla, NY, USA \\ ${ }^{4}$ The Neurological Institute, Columbia University, New York, NY, USA \\ Published online: 13 November 2021 \\ ๑ The Author(s) 2021
}

This article is part of the Topical Collection on Neuromuscular Disorders

Keywords Trials - FDA Expanded Access - Right to Try

\section{Abstract}

Purpose of Review People with fatal neuromuscular diseases such as ALS want to access investigational products. Trials are our preferred pathway for this, but most people with these diseases will not be able to participate due to restrictive inclusion criteria, travel burdens, or design features they will not accept. This leaves FDA Expanded Access Programs (EAPs), the Right To Try (RTT) pathway, and self-purchase of alternative and off-label treatments (A0Ts). Recent Findings A recent survey highlighted physician barriers to the above pathways, including lack of knowledge and concerns about time burdens and risks. Emerging resources are highlighted that can mitigate some of these concerns.

Summary With the information in this chapter, we hope that neuromuscular clinicians will feel more knowledgeable and confident in supporting patient request for investigational products. 


\section{Introduction}

While symptomatic treatments have improved, there are still no therapies that halt or reverse progression for fatal neuromuscular diseases such as ALS. It is therefore not surprising that people living with these serious, life-threatening diseases want access to investigational products. Clinical trials are the most obvious pathway for access to investigational therapies and the most important way to assess efficacy of an investigational products. However, currently less than $50 \%$ of people with neuromuscular diseases such as ALS will participate in a trial $\left[1^{\bullet}\right]$. Many would not meet the trial inclusion criteria and several barriers exist such as time and travel burdens, or the possibility of getting a placebo $[2 \bullet]$.
The following options exist for people living with severe neuromuscular diseases who want preapproval access to investigational therapy outside of a clinical trial (Table 1): "pre-approval access" pathways which include FDA Expanded Access Programs (EAPs), the Right To Try pathway (RTT), and self-purchase of alternative and offlabel treatments (AOTs). In the first part of this chapter, we will describe each of these options and the role that neuromuscular providers might play in assisting their patients to access investigational products outside of a clinical trial. In the second part, we discuss neuromuscular specialists' knowledge and concerns about these options. In the third and final part, we will highlight some resources that may make them more accessible.

\section{Part 1: The options}

\section{Clinical trials}

Clinical trials are our preferred pathway for accessing investigational therapies. Clinical trials have oversight (e.g., FDA, IRB, DSMB) which optimizes patient safety, and they have protocols that facilitate the gathering of robust outcome data. Clinical trials are able to generate and report safety and potential efficacy data on investigational products and in this way move the entire

Table 1 Neuromuscular provider roles in helping patients access experimental agents outside of a clinical trial

\begin{tabular}{|c|c|c|}
\hline Pathway Name & Description & Neuromuscular Neurologist's Role \\
\hline FDA Expanded Access Programs (EAPs) & $\begin{array}{l}\text { FDA approved pathways for use of a } \\
\text { regulated product in development, not } \\
\text { approved anywhere yet (3-5) }\end{array}$ & $\begin{array}{l}\text { Advisor, liaison with product owner, prescriber, } \\
\text { applies to FDA, applies to IRB, administers, follow- } \\
\text { up and report adverse events }(6,7)\end{array}$ \\
\hline Right to Try (RTT) & $\begin{array}{l}\text { Pathway which bypasses FDA for use of } \\
\text { a regulated product in development, } \\
\text { not approved anywhere yet } \\
(10,11)\end{array}$ & $\begin{array}{l}\text { Similar to EAPs except there is no application to the } \\
\text { FDA }\end{array}$ \\
\hline AOTs: Supplements & $\begin{array}{l}\text { Self-purchase of products the FDA } \\
\text { designates "Generally Regarded as } \\
\text { Safe" (15) }\end{array}$ & Advisor, follow-up \\
\hline AOTs: Off Label Use & $\begin{array}{l}\text { Use of a regulated and approved } \\
\text { product, off-label }\end{array}$ & Advisor, prescriber, follow-up \\
\hline $\begin{array}{l}\text { AOTs: FDA Personal Importation Policy } \\
\text { (PIP) }\end{array}$ & $\begin{array}{l}\text { FDA approved pathway for use of a } \\
\text { regulated product in development, } \\
\text { approved in another country } \\
\text { (17) }\end{array}$ & $\begin{array}{l}\text { Advisor, may provide letter to FDA (not required), } \\
\text { connects patient to source of drug (ex. 18), } \\
\text { provides prescription, letter, follow-up }\end{array}$ \\
\hline
\end{tabular}


field forward. Unfortunately, most people living with neuromuscular diseases like ALS will not be able to participate in clinical trials. They either would not meet any trial inclusion criteria, or they will decline participation due to travel and time burdens or trial design features they do not like such as placebos $[1 \bullet, 2 \bullet]$.

The FDA has long had "Expanded Access Programs" (EAPs) which allow patients with serious and life-threatening diseases who cannot participate in a trial to obtain pre-approval access to the investigational product being studied [3-5]. Physicians can request these for single patients (sometimes called "compassionate use") in an emergency or non-emergency situation, or for intermediate or large groups of patients [4]. According to their website, the FDA must agree that $[4,5]$

1. "The patient or patients to be treated have a serious or immediately lifethreatening disease or condition, and there is no comparable or satisfactory alternative therapy to diagnose, monitor, or treat the disease or condition;"

2. "The potential patient benefit justifies the potential risks of the treatment use and those potential risks are not unreasonable in the context of the disease or condition to be treated; and"

3. "Providing the investigational drug for the requested use will not interfere with the initiation, conduct, or completion of clinical investigations that could support marketing approval of the expanded access use or otherwise compromise the potential development of the expanded access use."

Physicians who wish to support eligible-patient requests for an EAP must first determine if the manufacturer is willing to provide the product at or below its cost. If not (as is often the case), there will be no way to obtain the product. If so, there are typically several tasks the physician must complete [5-7]. There may be a Confidential Disclosure Agreement and an Expanded Access Use Agreement and/or contract with the manufacturer. A Letter of Authorization (also called an LOA or Letter of Concurrence) and information about the investigational product (such as an Investigator's Brochure) must be obtained from the manufacturer and included in the subsequent IRB and FDA applications. A patient consent form and a treatment plan or protocol must be developed (and possibly agreed to with the manufacturer). FDA and IRB application forms must be completed. The FDA has historically approved 99\% of the EAP applications it has received across all diseases [8], and this approval typically takes between $24 \mathrm{~h}$ and 30 days. Institutional Pharmacy and Therapeutics Committee Approval forms may also be required. Once these applications are approved, the physician must receive and properly store the product (possibly through an agreement with their institution's Investigational Drug Service), and then treat and monitor the patient. Physicians must document the treatment in the medical record. They must also report 
serious adverse events encountered during treatment to the FDA and IRB [7] as they would in a clinical trial.

While there are several recent and ongoing examples of EAPs for patients with serious and life-threatening neuromuscular disease such as ALS [9], these tend to be less common than in oncology [10].

\section{Right to try}

A more recent option for obtaining pre-approval access to investigational products in development is the Right To Try (RTT) pathway [11]. This was made possible by the passage of Right To Try Laws in 41 states, and eventually at the federal level in 2018 [11]. The most significant difference between RTT and EAP pathways is that there is no requirement for a formal application to or approval by the FDA (Table 2). Indeed, the impetus for creating the RTT pathway was the supposition that the paucity of EAP options was the fault of the FDA [12]. According to the RTT website [11], eligible patients will meet the following criteria:

- "Be diagnosed with a life-threatening disease or condition;

- Have exhausted approved treatment options;

- Be unable to participate in a clinical trial involving the eligible investigational drug, as certified by a doctor, who is in good standing with her licensing organization and will not be compensated directly by the manufacturer for so certifying; and

- Give written informed consent regarding the risks associated with taking the investigational treatment."

Eligible products will meet the following criteria [11]:

- "Have completed an FDA-approved Phase 1 clinical trial,

Table 2 Comparing pre-reapproval access through Expanded Access and Right to Try [39]

\begin{tabular}{|l|l|l|}
\hline & $\begin{array}{l}\text { Expanded Access } \\
\text { Program (FDA) }\end{array}$ & Right To Try Law \\
\hline Requires FDA approval & Yes & No \\
\hline Requires IRB approval & Yes & $\begin{array}{l}\text { Not required federally but } \\
\text { may be required at specific } \\
\text { institutions }\end{array}$ \\
\hline $\begin{array}{l}\text { Requires physician approval } \\
\text { Obligates manufacturer to provide } \\
\text { drug }\end{array}$ & Yes & Yes \\
\hline $\begin{array}{l}\text { Informed consent required } \\
\text { Patient eligible for clinical trial }\end{array}$ & No & No \\
\hline & & Yes \\
\hline
\end{tabular}


- Be in an active clinical trial intended to form the basis of an application for approval or be the subject of an application for approval that has been filed with the FDA, and

- Be in ongoing active development or production and not discontinued by the manufacturer or placed on clinical hold."

Physicians who wish to support eligible-patient requests for a product via RTT engage in most of the same steps they would in an EAP, with the exception of the initial FDA application [13].

There are very few instances of people living with fatal neuromuscular diseases accessing investigational products via RTT. For example, we are aware of only 2 people living with ALS who ever used RTT. There might be several reasons for this including manufacturers who are either unable to or reluctant to provide their products outside of a trial, and physicians who might not know how to use this pathway or might have concerns about experimentation outside of a trial. RTT did not address either of these barriers. Ironically, by removing FDA oversight, RTT has probably made physicians even less enthusiastic about supporting patient requests for experimental products outside of a trial [14].

\section{Alternative and off-label treatments (AOTs)}

For the vast majority of people living with fatal neuromuscular diseases, the most common path for accessing experimental products will be self-purchase of alternative and off-label treatments (AOTs). This broad category includes products the FDA classifies "Generally Regarded as Safe" (GRAS) [15], purchasable in stores or online without a prescription. Examples include vitamins and supplements. It includes therapies that may require a physician prescription and have FDA approval for another indication (off-label). An example of off-label prescription was when some people with ALS requested prescriptions for the FDA-approved antibiotic minocycline while a trial of this was underway [16]. Finally, it includes prescription medications that are only approved and available in other countries but can be imported via the FDA Personal Importation Policy (PIP) [17]; some people living with ALS imported Edaravone before it was FDA approved, and some are currently importing Clenbuterol $[18,19]$. The FDA's exact language regarding the PIP is as follows [20]:

"In most circumstances, it is illegal for individuals to import drugs into the United States for personal use. This is because drugs from other countries that are available for purchase by individuals often have not been approved by FDA for use and sale in the United States. For example, if a drug is approved by Health Canada (FDA's counterpart in Canada) but has not been approved by FDA, it is an unapproved drug in the United States and, therefore, illegal to import. FDA cannot ensure the safety and effectiveness of drugs that it has not approved. 
FDA, however, has a policy explaining that it typically does not object to personal imports of drugs that FDA has not approved under certain circumstances, including the following situation:

- The drug is for use for a serious condition for which effective treatment is not available in the United States;

- There is no commercialization or promotion of the drug to U.S. residents;

- The drug is considered not to represent an unreasonable risk;

- The individual importing the drug verifies in writing that it is for his or her own use, and provides contact information for the doctor providing treatment or shows the product is for the continuation of treatment begun in a foreign country; and

- Generally, not more than a 3-month supply of the drug is imported."

Physicians wishing to support their patient's interest in the AOT path may be called upon to review their potential mechanisms, pre-clinical data, case reports, trials, and risks, and to advise the best sources and/or dosages. They may be called upon to write a prescription for an off-label use and to try to complete prior authorizations from insurance companies. These prior authorizations are often unsuccessful which means that the patient will have to pay for the product. In the case of the PIP, the physician may need to provide a prescription and a letter stating that the patient has a serious and incurable medical condition and that they will monitor the patient during treatment [21].

When people with neuromuscular diseases request access to investigational therapies, our first step is to review the clinical trial landscape and identify a clinical trial that they may be eligible for. If there are no clinical trials available, then our next step is to review investigational therapies that may be available through expanded access. Subsequently, should there be no clinical trial or EAP program available, then typically our next step is to review the risks and benefits of various AOTs.

\section{Part 2: Neuromuscular providers' knowledge and concerns}

A recent online survey of neuromuscular neurologists highlights their knowledge and concerns about accessing investigational products for patients outside of a trial [22•]. Over 1 month, multiple links to this 19 question survey were sent to 132 trial site investigators in the Northeast ALS Consortium (NEALS) [23] and 1400 members of the American Academy of Neurology Neuromuscular Section's Synapse Online Community [24]. Seventy-five neuromuscular neurologists completed the survey, in an average time of $4 \mathrm{~min}$. Responders identified themselves as seasoned (with $87 \%$ in practice for at least 10 years), academics (78\% in academic medical centers/teaching hospitals), and who had participated as investigators in ALS trials (75\%). Most responders said they had been asked by their patients to help procure experimental products, $28 \%$ via EAPs, $33 \%$ via RTT, and $16 \%$ via PIP. Yet more 
than $80 \%$ of responders had never tried to use any of these. Many admitted an incomplete understanding of these pathways. Responders were asked to rate their understanding on a scale from 0 to 100, where 100 means perfect. For EAPs, the mean score was 59, with 20 responses under 50. For RTT, the mean score was 67, with 13 responses under 50. For PIP, the mean score was 33, with 49 responses under 50. Beyond the lack of understanding, specific concerns responders raised with regard to procuring experimental products outside of a trial are listed by frequency in Fig. 1. These include uncertain risk-benefit ratio, facilitating false hope, financial harm to the patient and family, harm to mainstream research studies, physical harm to the patient, physician time and effort, and fear of being sued if something goes wrong. These concerns were similar to those identified in another survey of physician attitudes toward expanded access [25].

To help address some of these concerns, online and institutional resources (described in the next section) are available to help neuromuscular specialists delineate the benefits and risks of a particular product, and to better understand and complete the steps they must take to assist patients with

\section{Which of these concerns do you have about assisting ALS patients with trying treatments not yet approved by the FDA? (check all that apply)}

\section{Answered: $75 \quad$ Skipped: 0}

\begin{tabular}{|c|c|c|c|}
\hline ANSWER CHOICES & 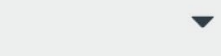 & RESPONSES & $\nabla$ \\
\hline - Uncertain risk benefit ratio & & $84.00 \%$ & 63 \\
\hline Facilitating false hope & & $78.67 \%$ & 59 \\
\hline Financial harm to patient and family & & $76.00 \%$ & 57 \\
\hline Could harm mainstream research studies & & $74.67 \%$ & 56 \\
\hline P Physical harm to patient & & $70.67 \%$ & 53 \\
\hline Takes too much physician time and effort & & $36.00 \%$ & 27 \\
\hline Fear of being sued if something goes wrong & & $13.33 \%$ & 10 \\
\hline Other (please specify) & Responses & $6.67 \%$ & 5 \\
\hline
\end{tabular}

Fig. 1. Neuromuscular neurologists answers. 
pre-approval access to investigational therapy. Time burdens are involved, but these are improving. Prior to 2016, physician time to complete the FDA application for a single patient EAP was estimated to be about $8 \mathrm{~h}$, and the entire application process took around 100 person-hours [25]. Currently this application takes less than $1 \mathrm{~h}$ to complete [26]. Of note, in addition to the FDA application, there are several other steps that will take additional physician time and institutional resources to successfully provide launch an EAP. In an informal survey of Duke investigators involved in EAPs across different disease states, total physician time required was $2-5 \mathrm{~h}$ per participant [27]. In addition to time, funding is needed to support the work required to monitor EAP participants. The Healey ALS Center at Massachusetts General Hospital (MGH) has accumulated significant experience with ALS EAPs, having conducted 12 EAPs involving more than 120 participants so far. Their cost to support one EAP participant was estimated to be about $\$ 10,000$ per year [28]. These costs include clinical research coordinator and physician time in addition to resources for data collection and safety monitoring. The need for adequate site resources should not be underestimated and, unlike a clinical trial, drug manufacturers usually do not fund the site resources needed to participate in EAPs or RTT. As described in the next section, there are emerging programs that may help physicians obtain these necessary resources. In terms of potential liability, we are not aware of any physician ever being successfully sued for helping a patient obtain an experimental treatment outside of a trial. This seems especially unlikely with EAPs, since they have both FDA and IRB oversite. RTT language specifically states, "A manufacturer, distributor, prescriber, dispenser, possessor, or user of such a treatment has no liability regarding the treatment" [29].

Neuromuscular neurologists' concern about these pathways potentially harming research, one that is shared by many manufacturers, is also likely unfounded. These concerns likely stem specifically from fears about detrimental effects on enrollment, and potential shutdowns of studies in case adverse events occur on an experimental product being used outside of a trial. EAPs and RTT pathways are reserved for patients who are ineligible to enroll in trials $[4,5,10]$ and there are multiple examples of clinical trials continuing to enroll at or better than background rates while an EAP was underway simultaneously [30, 31]. Further, there is no evidence that information from an EAP ever had a significant adverse effect on drug development. In a review of 1033 EAPs conducted over 10 years, there were only 2 brief temporary holds on trials from deaths observed in EAPs [32]. Between 2010 and 2016, new drug applications that included an EAP were significantly more (not less) likely to be approved by the FDA [32].

\section{Part 3: Useful resources}

Several resources are available to assist physicians who want to support their patients' request for investigational products. 


\section{Finding products}

The websites www.clinicaltrials.gov and www.neals.org can be used to find products for a given disease that are being offered in trials or EAPs. Manufacturer's websites will sometimes also show whether they are offering their products in trials or EAPs and to whom (e.g., [33]). The website www.alsuntangled.com can be used to find information on AOTs, including objective grading of each product's potential mechanisms, pre-clinical data, case reports, trials, and risks, as well as information about dosing and sources [34•].

Many academic institutions have offices that will assist physicians with the above-described EAP requirements such as agreements with the manufacturer, FDA, IRB, Pharmacy and Therapeutics Committee, and Investigational Drug Service applications [35]. The NIH Center for Leading Innovation and Collaboration website provides a comprehensive, 10-step guide for physicians who want to participate in EAPs, including templates for completing the manufacturer agreement/contract, FDA application, and IRB application [36••].

\section{Funding}

There are new and emerging sources of funding for EAPs. These include grants from patient advocacy groups; for example, I Am ALS recently funded an intermediate size EAP of verdiperstat for patients with ALS who do not qualify for the HEALEY ALS Platform Trial [37]. The proposed bill "Accelerating Access to Critical Therapies Act (ACT for ALS)" [38] might establish federal funding that could be utilized by physicians to cover the site resourced needed for running an EAP and also by small manufacturers to cover the creation of additional product.

\section{Conclusions}

Patients with serious and life-threatening neuromuscular diseases such as ALS are increasingly interested in access to investigational products. While clinical trials are the preferred way to access and evaluate the safety and efficacy of these products, many patients are unable to participate in trials. For people who are unable to participate in clinical trials, EAPs, RTT, and AOT pathways are available to facilitate access to investigational products. Neuromuscular specialists play critical roles in helping patients obtain products through these pathways. Emerging educational, institutional, and financial resources might facilitate neuromuscular physicians' support. 


\section{Conflict of Interest}

Richard Bedlack: Dr. Bedlack has research funding from the ALS Association, Healey Center, Orion, and MediciNova. He serves as a consultant for AB Science, Alexion, ALSA, Amylyx, Biogen, Brainstorm Cell, Corcept, Cytokinetics, GenieUs, Guidepoint, ITF Pharma, Mallinkrodt, New Biotic, Orphazyme, Shinkei, and Woolsey Pharma.Merit Cudkowicz: Nothing to disclose.Hamza Khan-tareen: Nothing to disclose.Jinsy A. Andrews: Dr. Andrews serves as a consultant for AL-S pharma, Amylyx, Biogen, Cytokinetics, Denali, Orphazyme, and Wave Therapeutics. She receives research funding from Alexion, Biogen, Cytokinetics, Orion, MGH/Healey Center for ALS, and NIH/NeuroNEXT.

Open Access This article is licensed under a Creative Commons Attribution 4.0 International License, which permits use, sharing, adaptation, distribution and reproduction in any medium or format, as long as you give appropriate credit to the original author(s) and the source, provide a link to the Creative Commons licence, and indicate if changes were made. The images or other third party material in this article are included in the article's Creative Commons licence, unless indicated otherwise in a credit line to the material. If material is not included in the article's Creative Commons licence and your intended use is not permitted by statutory regulation or exceeds the permitted use, you will need to obtain permission directly from the copyright holder. To view a copy of this licence, visit http:// creativecommons.org/licenses/by/4.0/.

\section{References}

Papers of particular interest, published recently, have

been highlighted as:

- Of importance

•• Of major importance

1.• Bedlack RS, Pastula DM, Welsh E, Pulley D, Cudkowicz M. Scrutinizing enrollment in ALS clinical trials: room for improvement? Amyotrophic Lateral Sclerosis 2008;9:257-265.

Highlights the low enrollment in ALS trials.

2.• Bedlack RS, Wicks Paul, Heywood J, Kasarskis E. Modifiable barriers to enrollment in American ALS research studies. Amyotrophic Lateral Sclerosis 2010;11:502-507.

Explains some of the barriers to enrollment in ALS trials, only some of which are easily modifiable.

3. Nichols E; Institute of Medicine (US) Roundtable for the Development of Drugs and Vaccines Against AIDS. Expanding access to investigational therapies for HIV infection and AIDS: March 12-13, 1990 Conference Summary. Washington (DC): National Academies Press (US). 1991;1. Historical Perspective. Available from: https://www.ncbi.nlm.nih.gov/books/NBK234129/

4. US Food and Drug Administration webpage on Expanded Access. https://www.accessdata.fda.gov/ scripts/cdrh/cfdocs/cfcfr/CFRSearch.cfm?CFRPart= 312\&showFR=1\&subpartNode=21:5.0.1.1.3.9 (2020). Accessed 5-May-2021.

5. National Institute of Health Center for Leading Innovation \& Collaboration. https://clic-ctsa.org/ groups/teamss/navigating-expanded-access\#section 1 (2020). Accessed 6-May-2021.

6. National Institute of Health Center for Leading Innovation \& Collaboration. https://clic-ctsa.org/ groups/teamss/navigating-expanded-access\#section3 (2020). Accessed 6-May-2021.

7. National Institute of Health Center for Leading Innovation \& Collaboration. https://clic-ctsa.org/ groups/teamss/navigating-expanded-access\#section9 (2020). Accessed 6-May-2021.

8. US Food and Drug Administration webpage on Expanded Access (compassionate use) submission data. https://www.fda.gov/news-events/expanded-access/ expanded-access-compassionate-use-submission-data (2020). Accessed 7-May-2021.

9. US National Library of Medicine Clinical Trials Database. https://clinicaltrials.gov/ct2/results? cond= ALS\&term $=$ expanded + access \& cntry $=\&$ state $=\&$ city $=\&$ dist=(2021). Accessed 8-May-2021.

10. US National Library of Medicine Clinical Trials Database. https://clinicaltrials.gov/ct2/results?cond= Cancer\&term $=$ expanded + access $\&$ cntry $=\&$ state $=\&$ city=\&dist=(2021). Accessed 8-May-2021. 
11. Right To Try website. https://righttotry.org/aboutright-to-try/(2017). Accessed 9-May-2021.

12. Right To Try website. http://righttotry.org/dead-onarrival/(2017). Accessed 9-May-2021.

13. US National Library of Medicine Clinical Trials Database. http://righttotry.org/helping-a-patient-securetreatment-under-right-to-try-is-easy-and-up-to-you/ (2017). Accessed 9-May-2021.

14. Helio News. https://www.healio.com/news/hematologyoncology/20200303/right-to-try-a-wellintentioned-butmisguided-law (2020). Accessed 9-May-2021.

15. US Food and Drug Administration webpage on GRAS. https://www.fda.gov/food/food-ingredientspackaging/generally-recognized-safe-gras (2019). Accessed 10-May-2021.

16. US National Library of Medicine Clinical Trials Database. https://clinicaltrials.gov/ct2/show/ NCT00047723?term=minocycline \& cond=ALS\& draw=2\&rank=1 (2017). Accessed 10-May-2019.

17. US Food and Drug Administration webpage on Personal Importation. https://www.fda.gov/industry/ import-basics/personal-importation (2020). Accessed 11-May-2021.

18. The Social MedWork page on Clenbuterol. https:// thesocialmedwork.com/tonil-clenbuterol (2021). Accessed 11-May-2021.

19. US National Library of Medicine Clinical Trials Database. https://clinicaltrials.gov/ct2/show/ NCT04245709?term=clenbuterol\&cond=ALS\& draw $=2 \&$ rank=1 (2017). Accessed 11-May-2021.

20. US Food and Drug Administration webpage on Personal Importation. https://www.fda.gov/about$\mathrm{fda} /$ fda-basics/it-legal-me-personally-import-drugs (2020). Accessed 11-May-2021.

21. The Social MedWork. https://thesocialmedwork. com/custom/files/import-guides/TSM-Physiciansguide-to-importing-medicine.pdf (2021). Accessed 12-May-2021.

22. Bedlack R. Neurologists' views on "Right to Try"; Salem witch trials, revisited. Amyotroph Lateral Scler and Frontotemp Degen 2017;19s2:24.

Elucidates neuromuscular neurologists' knowledge of and concerns about EAPs, RTT and PIP.

23. Northeast ALS Consortium. https://www.neals.org (2021). Accessed 12-May-2021.

24. American Academy of Neurology Synapse page. https://synapse.aan.com/mycommunities (2021). Accessed 14-May-2021.

25. Bunnik E, Aarts N, van de Vathorst S. Views and experiences of physicians in expanded access to investigational drugs. Clin Ther. 2017;39:e96.

26. Regulatory Affairs Professional Society. http://www. raps.org/Regulatory-Focus/News/2015/02/04/21243/ From-100-Hours-to-1-FDA-Dramatically-Simplifiesits-Compassionate-Use-Process/ (2015). Accessed 15-May-2021.

27. Bedlack unpublished data
28. Northeast ALS Consortium. https://www.neals.org/ for-people-with-als-caregivers/educational-webinars/ als-drug-development-webinar-series-part-4-siteconsiderations (2021). Accessed 15-May-2021.

29. United States Congress website. https://www. congress.gov/bill/115th-congress/senate-bill/204? $\mathrm{q}=\% 7 \mathrm{~B} \% 22$ search $\% 22 \% 3 \mathrm{~A} \% 5 \mathrm{~B} \% 22$ right+ to + try $\% 22 \% 5 \mathrm{D} \% 7 \mathrm{D} \& \mathrm{r}=1$ (2017). Accessed 15-May-2021.

30. Institute of Medicine: Chapter 3-Evaluation of expanded access programs. In: Expanding Access to Investigational Therapies For HIV Infection and AIDS. 1991. https://www.nap.edu/read/1778/ chapter/5\#30. Accessed 17-May-2021.

31. Cudkowicz M, van den Berg L, Shefner J, Mitsumoto H, Mora J, Ludolph A, Hardiman O, et al. Dexpramopexole versus placebo for patients with amyotrophic lateral sclerosis (Empower). Lancet Neurol. 2013;12:1059-67.

32. Jarrow J, Lemery S, Bugin K, Khozin S, Moscicki R. Expanded access of investigational drugs: the experience of the center of drug evaluation and research over a 10-year period. Ther Innov Regul Sci. 2016;50:705-9.

33. Biogen webpage on access programs. https://www. biogen.com/en_us/access-programs.html (2021). Accessed 1-July-2021.

34. ALSUntangled. https://www.alsuntangled.com/ completed-reviews/ (2021). Accessed 1-July-2021.

Lists and critically evaluations various AOTs.

35. Duke University Office of Regulatory Affairs and Quality. https://medschool.duke.edu/research/researchsupport-offices/office-regulatory-affairs-and-quality/ expanded-access (2021). Accessed 1-July-2021.

36.• National Institute of Health Center for Leading Innovation \& Collaboration https://clic-ctsa.org/ groups/teamss/navigating-expanded-access (2020). Accessed 6-May-2021.

Offers a step-by-step guide for clinicians who want to offer expanded access programs.

37. Massachusetts General Hospital. https://www. massgeneral.org/neurology/als/news/2020-12-18iamals-eap-grant (2021). Accessed 1-July-2021.

38. United States Congress website. https://www.congress. gov/bill/116th-congress/house-bill/7071?s=1\&r=7 (2021). Accessed 1-July-2021.

39. Lynch H, Zettler P, Sarpatwari A. Promoting patient interest in implementing the federal right to try act. JAMA. Published online August 13, 2018.

\section{Publisher's Note}

Springer Nature remains neutral with regard to jurisdictional claims in published maps and institutional affiliations. 